\title{
Effect of Temperature and Duration Time of Maceration on Nitrate Content of Vernonia cinerea (L.) Less.: Circumscribed Central Composite Design and Method Validation
}

\author{
Chaowalit Monton $\mathbb{D}^{1}$ and Chitradee Luprasong $\mathbb{D D}^{2}$ \\ ${ }^{1}$ Drug and Herbal Product Research and Development Center, College of Pharmacy, Rangsit University, Pathum Thani 12000, Thailand \\ ${ }^{2}$ Sun Herb Thai Chinese Manufacturing, College of Pharmacy, Rangsit University, Pathum Thani 12000, Thailand \\ Correspondence should be addressed to Chaowalit Monton; chaowalit@rsu.ac.th and Chitradee Luprasong; chitradee.l@rsu.ac.th
}

Received 27 January 2019; Accepted 21 March 2019; Published 2 May 2019

Academic Editor: Salam A. Ibrahim

Copyright (C) 2019 Chaowalit Monton and Chitradee Luprasong. This is an open access article distributed under the Creative Commons Attribution License, which permits unrestricted use, distribution, and reproduction in any medium, provided the original work is properly cited.

\begin{abstract}
Vernonia cinerea (L.) Less. is a herbal plant in Family Asteraceae. It can be used as a smoking cessation aid due to the fact that it contains nitrate which can induce tongue numbness and cause less favor of cigarette smell and taste. The aim of this work was to investigate the effect of maceration temperature and time on the nitrate content of $V$. cinerea. A circumscribed central composite experimental design was applied in the work. Two factors (temperature and duration time) were investigated and two responses (yield of the extraction and nitrate content) were monitored. The high performance liquid chromatography using for quantitative analysis of nitrate content was validated. The HPLC response was linear $\left(\mathrm{R}^{2}=1.000\right)$ in range of $10-100 \mu \mathrm{g} / \mathrm{mL}$. The HPLC method was specific, precise, and accurate. The maceration temperature and time were varied from 40 to $100^{\circ} \mathrm{C}$ and 10 to 60 min, respectively. Results showed that maceration at high temperature and long duration time gave the simultaneous high yield of the extraction and nitrate content. The prediction by the computer software, Design-Expert, was stable, reliable, and accurate. The optimal condition that provided simultaneous high yield of the extraction and nitrate content was achieved when extraction was at $99.5^{\circ} \mathrm{C}$ for 56.4 min. $V$. cinerea extracted using the optimal condition gave the yield of the extraction and nitrate content of $15.6 \%$ and $0.610 \%$, respectively. In conclusion, maceration temperature and duration time had a positive effect on yield of the extraction and nitrate content of $V$. cinerea. Furthermore, the optimal condition in this work could be used as a guide for extraction of $V$. cinerea to obtain the high yield of the extraction as well as nitrate content.
\end{abstract}

\section{Introduction}

Vernonia cinerea (L.) Less. is a plant in Family Asteraceae. It has several activities such as antioxidant activity [1-5], anti-inflammatory activity $[6,7]$, and radioprotective activity [8]. Furthermore, it also has antitumor activity, antimicrobial activity, antidiabetic activity, etc. [9]. In Thailand, this plant is officially included in the National List of Essential Medicines use as a smoking cessation aid. V. cinerea contains a low content of nicotine, so it may act as nicotine replacement therapy. Naijitra and Cheoymang report nicotine in leaf extracts of $V$. cinerea is $0.115 \%$ [10]. In addition, Ketsuwan et al. report nicotine in flower extracts is $0.123 \%$ and in leaf extracts is $0.154 \%$ [3]. V. cinerea also contains nitrate salt that can induce tongue numbness and cause less favor of cigarette smell and taste [11, 12]. Nitrate contents in $V$. cinerea stem extracts and leaf extracts are previously reported; $21 \%$ and $19 \%$, respectively [3]. Among preparations using for smoking cessation, $V$. cinerea preparation have daily cost cheaper than that of standard preparations; bupropion, nicotine gums, or nicotine patches [13]. So, $V$. cinerea is an alternative aid of smoking cessation with cost-saving manner. There are a recent systematic review and meta-analysis of five randomized clinical trials with 347 smokers included; the results show that $V$. cinerea has potential efficacy for smoking cessation with no significant difference of adverse events between the treatment group and control group [14]. Nowadays, $V$. cinerea is developed into several dosage forms, i.e., tea [13, 15, 16], capsules [17], lozenges [18], juice [19], coffee [20], cookies [11], jelly candies [12], and pastilles [21]. 
TABLE 1: Factors and responses of model conditions of circumscribed central composite experimental design.

\begin{tabular}{lcccccc}
\hline \multirow{2}{*}{\begin{tabular}{c} 
Condition \\
\cline { 3 - 5 }
\end{tabular}} & \multicolumn{2}{c}{ Temperature } & \multicolumn{2}{c}{ Tactors } & \multicolumn{2}{c}{ Responses } \\
& Coded & Actual $\left({ }^{\circ} \mathrm{C}\right)$ & Coded & Actual (min) & Yield of the extraction (\%) & Nitrate content (\%) \\
\hline 1 & -1 & 48.8 & -1 & 17.3 & 8.4 & $0.315 \pm 0.008$ \\
2 & 1 & 91.2 & -1 & 17.3 & 10.4 & $0.368 \pm 0.000$ \\
3 & -1 & 48.8 & 1 & 52.7 & 10.0 & $0.372 \pm 0.000$ \\
4 & 1 & 91.2 & 1 & 52.7 & 15.2 & $0.486 \pm 0.000$ \\
5 & $-\sqrt{ } 2$ & 40.0 & 0 & 35.0 & 16.6 & $0.175 \pm 0.000$ \\
6 & $\sqrt{ } 2$ & 100.0 & 0 & 35.0 & 7.4 & $0.578 \pm 0.000$ \\
7 & 0 & 70.0 & $-\sqrt{ } 2$ & 10.0 & 13.6 & $0.258 \pm 0.001$ \\
8 & 0 & 70.0 & $\sqrt{ } 2$ & 60.0 & 11.4 & $0.536 \pm 0.001$ \\
9 & 0 & 70.0 & 0 & 35.0 & 11.4 & $0.467 \pm 0.000$ \\
10 & 0 & 70.0 & 0 & 35.0 & $0.402 \pm 0.000$ \\
\hline
\end{tabular}

The extraction of a plant is an important step to increase the concentration of the targeted plant bioactive compounds. Furthermore, it can provide a robust and reproducible extraction method that is independent of the variations of the plant raw materials [22]. The different conditions and different extraction techniques should be used for understanding the extraction selectivity of various plant active compounds [23]. The aim of this work was to investigate the effect of maceration temperature and time on the nitrate content of $V$. cinerea. The circumscribed central composite experimental design was applied in the work. Two factors (temperature and duration time) were investigated and two responses (yield of the extraction and nitrate content) were monitored. The method validation of high performance liquid chromatography (HPLC) for quantitative analysis of nitrate content was also performed. The authors expected that the optimal condition obtained from this work might be used as a guide for extraction of $V$. cinerea to obtain the simultaneous high of yield of the extraction as well as nitrate content.

\section{Materials and Methods}

2.1. Materials. Potassium nitrate and orthophosphoric acid (85\%) were purchased from Carlo Erba Reagents, France. Octylamine was purchased from Sigma-Aldrich, USA. Methanol (HPLC grade) was purchased from HoneywellBurdick \& Jackson, USA.

2.2. Plant Raw Material. The whole plant of $V$. cinerea was harvested from Buachet District, Surin Province, Thailand, in August 2018. The plant was identified by Ajarn Nirun Vipunngeun, Department of Pharmacognosy, College of Pharmacy, Rangsit University. The voucher specimen was coded as CM-CC001-1-08-2018 and deposited at Drug and Herbal Product Research and Development Center, College of Pharmacy, Rangsit University. The fresh V. cinerea was cut into small pieces and sun-dried. Then, they were pulverized and stored in a dry place until use.

2.3. Extraction of Nitrate and the Optimization. The circumscribed central composite experimental design was applied in the work. Two factors were investigated: temperature and time. Temperature and time were varied from 40 to $100^{\circ} \mathrm{C}$ and 10 to $60 \mathrm{~min}$, respectively. Traditionally, the plant was infused using boiling water and stand for a few minutes. In some cases, the decoction was used; the plant was boiled in hot water for approximately $15 \mathrm{~min}$. So the selected temperature and time range of this work was based on the traditional use of this plant. $V$. cinerea powder was extracted by maceration technique. Water was used as an extraction solvent. The $50 \mathrm{~mL}$ of water was added to $5 \mathrm{~g}$ of $V$. cinerea powder in a $100-\mathrm{mL}$ beaker. It was macerated in hot air oven (JS Research Inc., South Korea) in specific temperature and duration time as shown in Table 1, in which ten model conditions were designed. They were extracted for three times; the filtrates were pooled and then freeze-dried. The freeze-dried extracts were kept in a desiccator until use. The two responses were monitored: yield of the extraction and nitrate content. The optimization was performed using Design-Expert software (version 11.0.2.0) (Stat-Ease, Inc., USA). The $3 \mathrm{D}$ response surfaces of model conditions of yield of the extraction and nitrate content were produced. The predicted values vs. actual values plot and residuals vs. run plot were produced to ensure the reliability and stability of the prediction by the software. The desirability function was used to select the optimal condition $[24,25]$ that provided the simultaneous highest yield of the extraction and nitrate content.

2.4. HPLC Method Validation. The method validation was performed according to ICH guideline. Five topics were investigated: linearity and range, specificity, limit of detection (LOD) and limit of quantitation (LOQ), precision, and accuracy.

2.4.1. Linearity and Range. A stock solution of potassium nitrate $16.3 \mathrm{mg}$ (equivalent to nitrate $10 \mathrm{mg}$ ) was accurately weighed, dissolved in ultrapure water, and adjusted to the volume to $10 \mathrm{~mL}$. It was diluted into five concentration levels including $100,75,50,25$, and $10 \mu \mathrm{g} / \mathrm{mL}$. They were filtered using $0.45 \mu \mathrm{m}$ pore size syringe filter. They were injected into the HPLC instrument $(n=3)$ and a calibration curve 


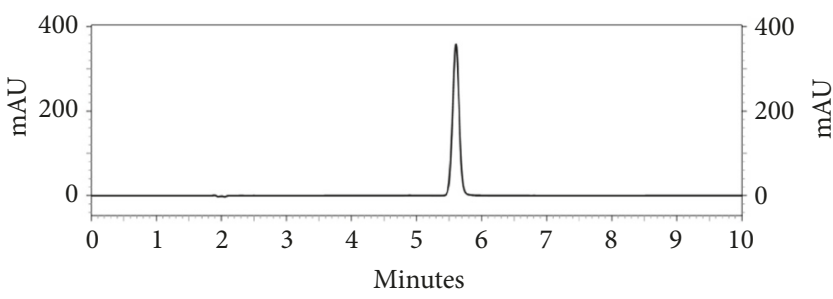

(a)

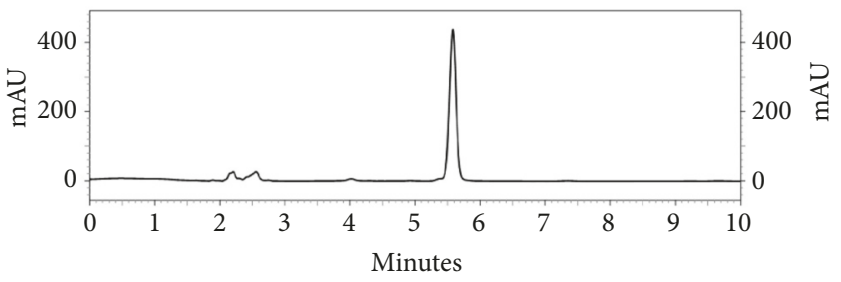

(b)

FIGURE 1: HPLC chromatograms of (a) nitrate $(50 \mu \mathrm{g} / \mathrm{mL})$ and (b) V. cinerea extract extracted from condition $9(2 \mathrm{mg} / \mathrm{mL})$.

of nitrate was constructed. Linear equation, coefficient of determination $\left(\mathrm{R}^{2}\right)$, and test range were reported.

2.4.2. Specificity. Specificity was determined by comparison of UV spectrum of the peak of standard nitrate with the peak of nitrate in $V$. cinerea extract. In case of the peak of $V$. cinerea extract, UV spectrum at three regions of the peak, upslope, center, and downslope, were monitored. The method was specific when UV spectrum at three regions of the peak of nitrate in $V$. cinerea extract was similar to UV spectrum of the peak of standard nitrate.

2.4.3. LOD and LOQ. LOD and LOQ were calculated from the slope of the calibration curve and standard deviation (SD) of the response of a blank solution from ten injections. LOD and LOQ were calculated as (1) and (2):

$$
\begin{aligned}
& L O D=\frac{3.3 \sigma}{S} \\
& L O Q=\frac{10 \sigma}{S}
\end{aligned}
$$

where $\sigma$ was the SD of the response of the blank solution and $\mathrm{S}$ was the slope of the calibration curve.

2.4.4. Precision. Repeatability and intermediate precision were determined. Three concentration levels of nitrate, 75, 50, and $25 \mu \mathrm{g} / \mathrm{mL}$, were prepared. They were analyzed by HPLC instrument in triplicate for each concentration. The percent relative standard deviation (\%RSD) from the analysis of each day for three consecutive days was reported as repeatability. The $\%$ RSD of pooled results from three days was reported as intermediate precision.

2.4.5. Accuracy. The accuracy was determined by the standard addition method and presented as percent recovery. Nitrate in three concentration levels, 75,50 , and $25 \mu \mathrm{g} / \mathrm{mL}$, was individually added to $V$. cinerea extract. They were analyzed by HPLC instrument in triplicate for each concentration and the percent recovery was calculated.

2.5. Quantitative Analysis of Nitrate Content. Nitrate content in $V$. cinerea was quantified using reversed-phase ioninteraction HPLC which was previously used for determination of nitrate in canned vegetable juices [26], vegetables [27], and sodium nitrate mouthwash [28, 29]. The quantitative analysis was performed by HPLC instrument Agilent 1260 infinity, Agilent Technologies, USA. The isocratic elution of $0.01 \mathrm{M}$ octylammonium orthophosphate ( $\mathrm{pH} 7.0)$ was used. It was prepared by dissolving $1.3 \mathrm{~g}$ octylamine in $30 \% \mathrm{v} / \mathrm{v}$ methanol, adjusting the $\mathrm{pH}$ with $10 \%$ orthophosphoric acid to 7.0 , and finally adjusting the volume to $1,000 \mathrm{~mL}$ using $30 \% \mathrm{v} / \mathrm{v}$ methanol. The separation was done on ACE Generix column $(150 \mathrm{~mm} \times 4.6 \mathrm{~mm}$, internal diameter, $5 \mu \mathrm{m})$ with a temperature of $25^{\circ} \mathrm{C}$. The flow rate of mobile phase was $0.8 \mathrm{~mL} / \mathrm{min}$. The injection volume was $10 \mu \mathrm{L}$. The detection wavelength was $213 \mathrm{~nm}$.

In case of $V$. cinerea extract, it was diluted by ultrapure water into the concentration of $2 \mathrm{mg} / \mathrm{mL}$, filtered using $0.45 \mu \mathrm{m}$ pore size syringe filter, and injected into HPLC instrument. The nitrate content of $V$. cinerea extract was calculated from the calibration curve of nitrate. Mean and SD of nitrate content were reported.

\section{Results and Discussion}

3.1. Method Validation Results. The HPLC method had linear equation of $\mathrm{y}=108,141 \mathrm{x}+45,243\left(\mathrm{R}^{2}=1.000\right)$ in the test range of $10-100 \mu \mathrm{g} / \mathrm{mL}$. The LOD and LOQ were 10 and 40 $\mathrm{ng} / \mathrm{mL}$, respectively. The HPLC chromatograms of standard nitrate and $V$. cinerea extract are shown in Figure 1. Nitrate was eluted at the retention time of $5.6 \mathrm{~min}$. According to the specificity of the analysis, this method was specific due to UV spectrum at upslope, center, and downslope of the peak of nitrate in $V$. cinerea extract was similar to $\mathrm{UV}$ spectrum of the peak of standard nitrate (Figure 2). Results of precision and accuracy are shown in Table 2 . Repeatability of the analysis had \%RSD less than $2 \%$ for the individual for three consecutive days. Moreover, intermediate precision performed from the analysis for three consecutive days was less than 5\%. The accuracy represented as percent recovery had the value close to $100 \%$; $97.58-102.46 \%$. These results indicated that the HPLC method was precise and accurate.

3.2. Optimal Condition for Extraction of $V$. cinerea. Factors and responses of model conditions of yield of the extraction and nitrate content are shown in Table 1. Condition 6 was the best condition providing the highest yield of the extraction as well as nitrate content while Condition 5 provided the lowest yield of the extraction and nitrate content. The range of nitrate content in plant raw material was $0.175-0.578 \%$ dependent on the extraction condition. The nitrate content in extracts ranged from 2.9 to $4.1 \%$ (data not shown), which was 
TABLe 2: Precision and accuracy results.

\begin{tabular}{lcccccc}
\hline \multirow{2}{*}{ Concentration $(\mu \mathrm{g} / \mathrm{mL})$} & \multicolumn{3}{c}{ Precision (\%RSD) } & Accuracy \\
& Depeatability & Spike concentration $(\mu \mathrm{g} / \mathrm{mL})$ & Intermediate & \%ecovery \\
\hline 25 & 0.24 & 0.03 & 0.09 & 0.50 & 50 & 102.46 \\
50 & 0.09 & 0.04 & 1.12 & 0.67 & 75 & 97.58 \\
75 & 0.07 & 0.07 & 0.13 & 0.28 & 101.68 \\
\hline
\end{tabular}

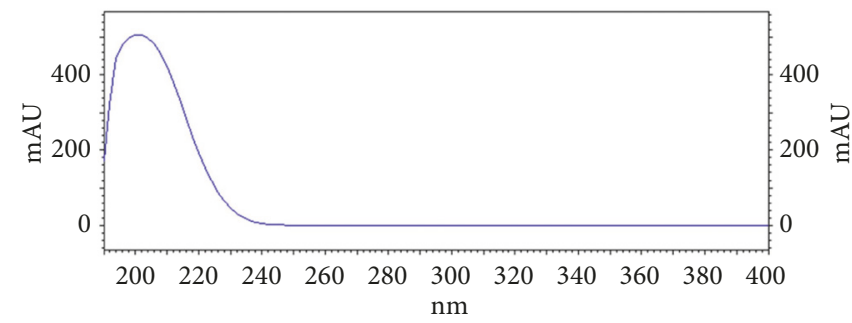

(a)

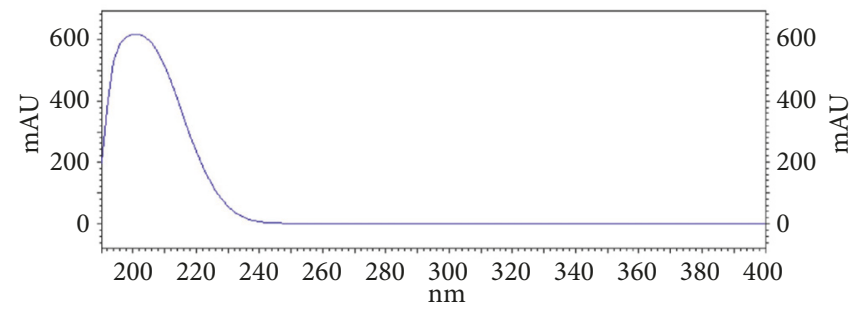

(b)

FIGURE 2: UV spectrums at (a) center of the peak of nitrate and (b) center of the peak of nitrate in V. cinerea.

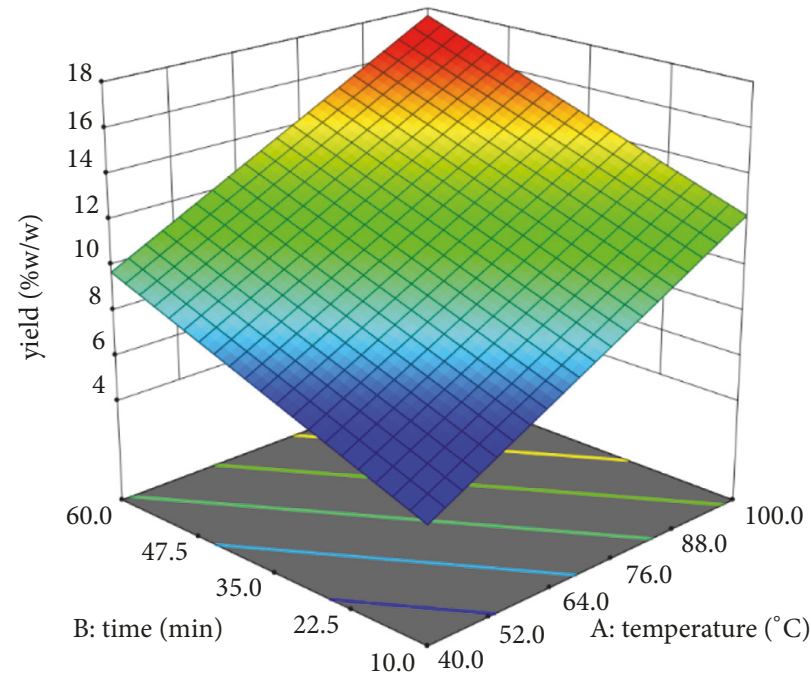

(a)

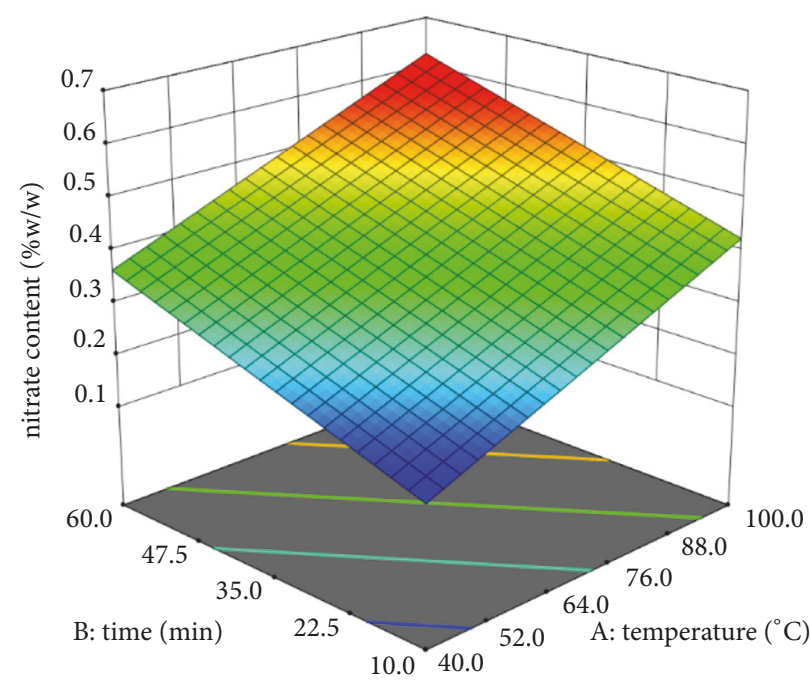

(b)

FIGURE 3: Response surfaces of model conditions of (a) yield of the extraction and (b) nitrate content.

lower than the previous report. Ketsuwan et al. reported that nitrate contents in $V$. cinerea stem extract and leave extract obtained from decoction were $21 \%$ and $19 \%$, respectively, while they were not found in flowers extract [3]. Figure 3 shows the 3D response surfaces of model conditions of yield of the extraction and nitrate content. The results revealed that yield of the extraction and nitrate content was high when the maceration is done at high temperature and long duration time. Conversely, yield of the extraction and nitrate content were low when the maceration is done at low temperature and short duration time. The equations for prediction of yield of the extraction and nitrate content when macerate is at different temperatures and duration times are shown in (3) and (4), respectively.

$$
\begin{aligned}
\text { Yield }(\%)= & -1.868 \\
& +0.131(\text { temperature }) \\
& +0.107(\text { time }) \\
\text { Nitrate content }(\%)=- & 0.049 \\
& +0.004(\text { temperature }) \\
& +0.004(\text { time })
\end{aligned}
$$

The above $3 \mathrm{D}$ response surfaces and equations revealed that maceration temperature and duration time had a positive effect on the yield of the extraction and nitrate content of $V$. cinerea. Extraction temperature and extraction time 
are the important factors affecting the content of chemical constituents of several plants. When temperature increased, the content of phenolic compound, flavonoid, and condensed tannins of Centella asiatica increased. However, the extraction time had the optimum value; too long extraction time led to the decomposition of plant chemical compounds [30]. $\mathrm{Lv}$ et al. investigated the effect of extraction temperature and extraction time on the content of amygdalin of two plants, apricot-kernel and Prunus tomentosa using reflux extraction. They found that when temperature and duration time increased, the content of amygdalin increased. However, when the maximum content is reached, amygdalin content was gradually decreased due to its decomposition [31]. The longer extraction time might lead to thermal instability and degradation of thermolabile compounds. The long duration time could destroy some polysaccharides such as polysaccharides of Hovenia dulcis peduncles [32] and polysaccharides of Angelica sinensis [33]. Moreover, the high extraction temperature combined with long extraction time also led to degradation of polysaccharides of Tricholoma mongolicum [34], mulberry fruit [35], and Astragalus cicer [36]. The effect of temperature and time of pressurized hot water extraction on the polyphenolic content of Thymus vulgaris was evaluated. The results showed that the highest yield of some polyphenols such as hydroxycinnamic acids, flavones, flavonols/flavanones, and total polyphenols was obtained when extraction at $100^{\circ} \mathrm{C}$ for $5 \mathrm{~min}$. Furthermore, they found that the higher extraction temperature and longer extraction time provided less diversity of above polyphenols. The 3,4dihydroxyphenyllactic acid was the only phenolic compound that mostly extracted at high temperature while the nonphenolic antioxidant was favored at the higher extraction temperature and extraction time [37]. Dent et al. reported extraction temperature had a positive effect on mass fractions of rosmarinic acid and luteolin-3-glucuronide of Salvia officinalis, while extraction time had a positive effect only on mass fractions of luteolin-3-glucuronide [38]. Martins and da Conceicao revealed extraction time had a significant effect on rosmarinic acid and caffeic acid of Apeiba tibourbou extracted using ultrasound-assisted extraction while extraction temperature had no effect on both rosmarinic acid and caffeic acid [39]. Kuzmanović et al. extracted the phenolic compound from corn silage using high temperature and high pressure reactor. They varied several extraction parameters. The optimization results showed that temperature was the most significant factor affecting phenolic compound content [40]. The above results indicated that optimal temperature and time of the extraction procedure should be optimized to obtain the maximum content of targeted plant active constituents.

Figure 4 shows predicted vs. actual value plots and internally studentized residuals vs. run number plots of model conditions of yield of the extraction and nitrate content. The predicted vs. actual value plots had moderate to high $\mathrm{R}^{2}$ indicating that the predicted value was correlated to the actual (or experimental) value. The internally studentized residuals vs. run number plots displayed that the data was distributed within 95\% confident interval. The above data could approve the reliability and stability of the prediction
TABLE 3: Predicted values, experimental values, and percent error of the prediction.

\begin{tabular}{lccc}
\hline Responses & $\begin{array}{c}\text { Predicted } \\
\text { value }\end{array}$ & $\begin{array}{c}\text { Experimental } \\
\text { value }\end{array}$ & Error (\%)* \\
\hline $\begin{array}{l}\text { Yield of the } \\
\text { extraction (\%) }\end{array}$ & 17.2 & $15.5 \pm 0.14$ & -10.97 \\
Nitrate content (\%) & 0.610 & $0.610 \pm 0.001$ & 0.00 \\
\hline
\end{tabular}

$* \%$ Error $=($ experimental value - predicted value $) /$ experimental value $\times 100$.

[41, 42]. The optimal condition provided the highest yield of the extraction and nitrate content obtained from computer software, Design Expert, were $99.5^{\circ} \mathrm{C}$ and $56.4 \mathrm{~min}$. The desirability of the prediction was 1.000 . According to the prediction value, extraction using this optimal condition gave the yield of the extraction and nitrate content of $17.2 \%$ and $0.610 \%$, respectively while the experiments revealed that extraction using this optimal condition provided the yield of the extraction and nitrate content of $15.5 \%$ and $0.610 \%$, respectively. Comparison between the predicted value and experimental value found that percent error of the prediction was $-10.97 \%$ and $0 \%$ for yield of the extraction and nitrate content, respectively (Table 3 ). These results indicated that computer software could predict in an accurate manner. However, we suggested that extraction at $100^{\circ} \mathrm{C}$ could be used due to the fact that it was an easier manner for the extraction setting.

\section{Conclusions}

The HPLC was validated in this work and used for quantitative analysis of nitrate content of $V$. cinerea. The HPLC method had the linear response and it was specific, precise, and accurate. The circumscribed central composite experimental design was applied in the work. Effect of maceration temperature and duration time on yield of the extraction and nitrate content were investigated. The maceration at high temperature and long duration time provided the high yield of the extraction as well as nitrate content. This result indicated that the maceration temperature and duration time had a positive effect on yield of the extraction and nitrate content of $V$. cinerea. However, the other factors also affected the yield of the extraction and nitrate content of $V$. cinerea such as plant variation, harvesting location, harvesting period, extraction technique, and solid-to-solvent ratio. We suggested that the optimal condition reported in this work could be used as a guide for extraction of $V$. cinerea to obtain the simultaneous high yield of the extraction and nitrate content.

\section{Data Availability}

The data used to support the findings of this study are available from the corresponding author upon request.

\section{Conflicts of Interest}

All authors declare that they have no conflicts of interest. 


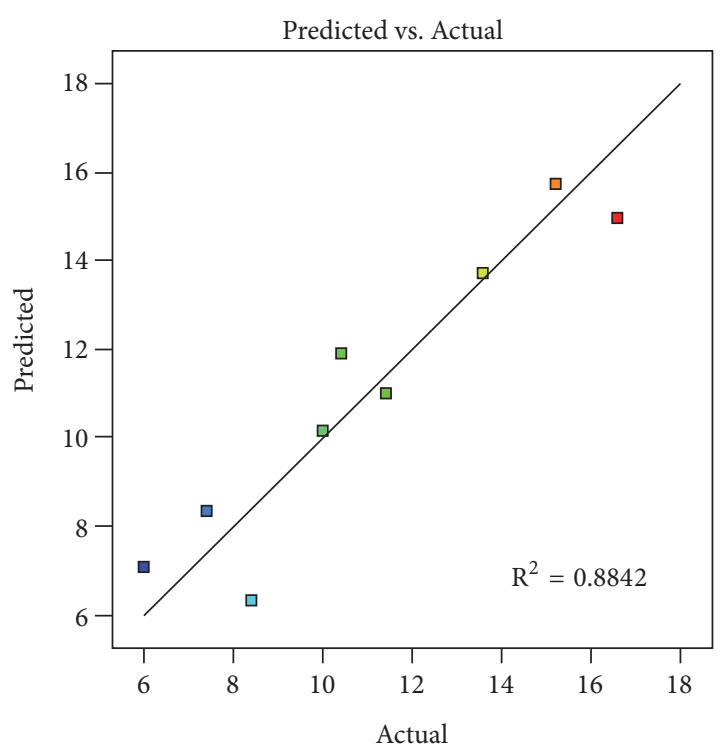

(a)

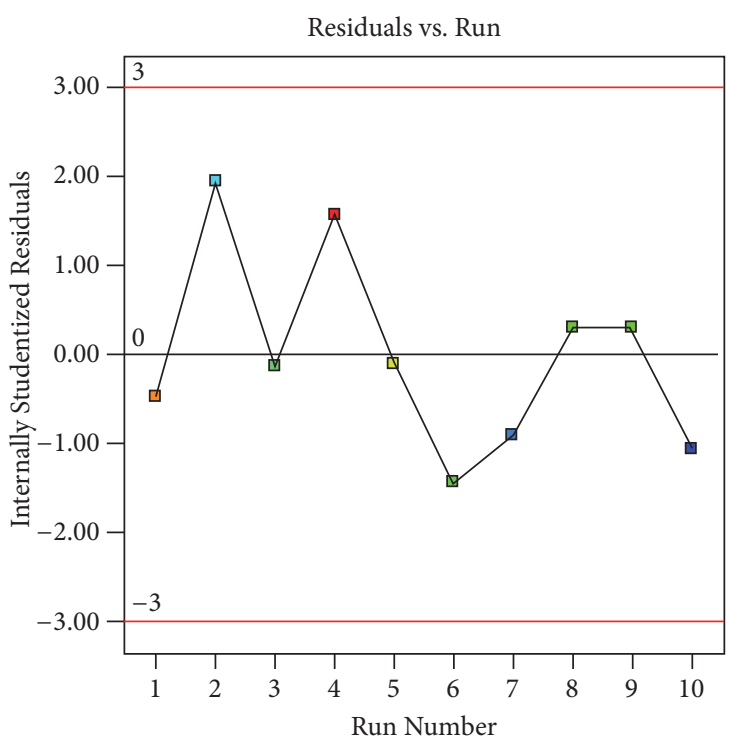

(c)

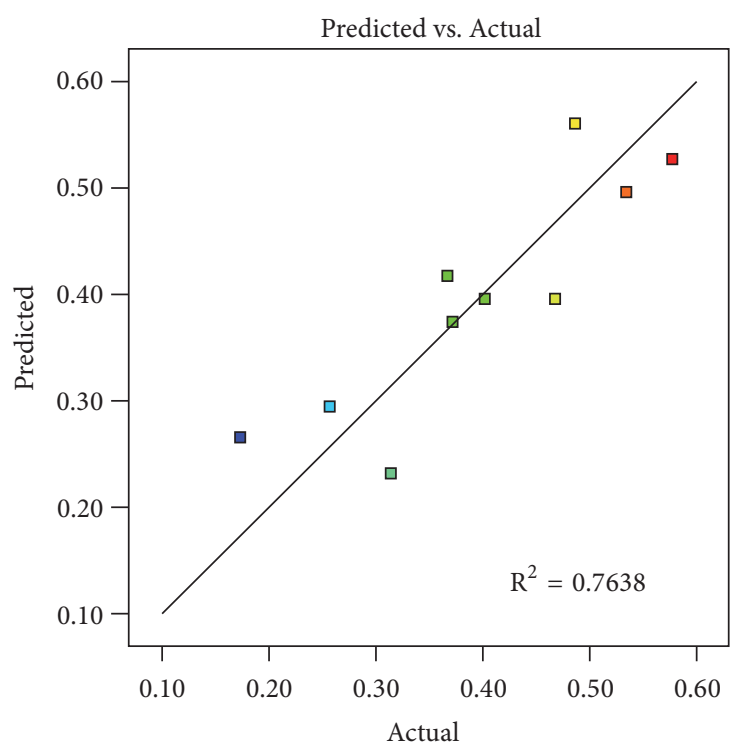

(b)

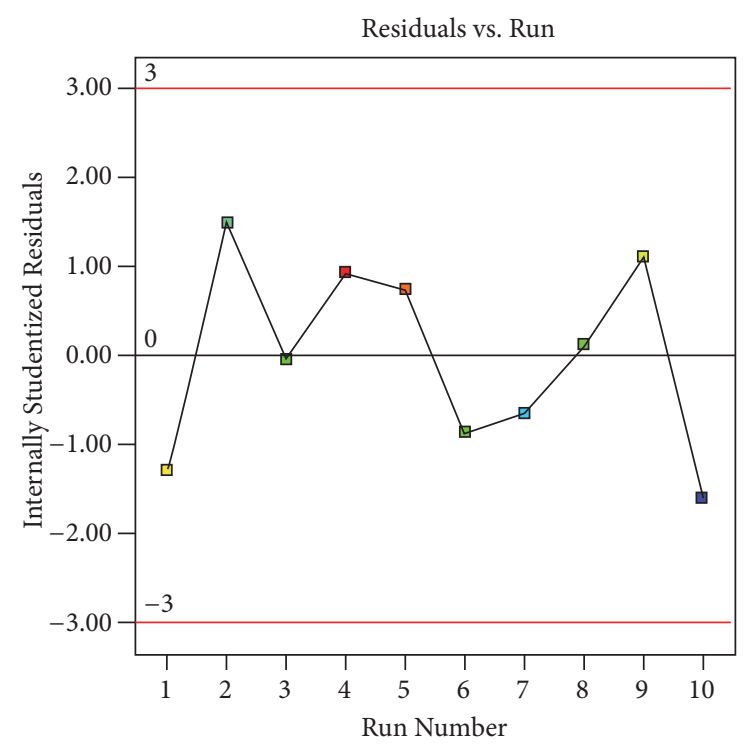

(d)

FIGURE 4: Predicted vs. actual value plots of model conditions of (a) yield of the extraction and (b) nitrate content and residuals vs. run plots of model conditions of (c) yield of the extraction and (d) nitrate content.

\section{Acknowledgments}

The authors would like to thank Mr. Kasidit Pisawong and Miss Chanita Saekow for research assistance. We also acknowledge College of Pharmacy, Rangsit University, for facilities support. This research did not receive any specific grant from funding agencies in the public, commercial, or not-for-profit sectors.

\section{References}

[1] O. R. Alara, N. H. Abdurahman, H. K. Afolabi, and O. A. Olalere, "Efficient extraction of antioxidants from Vernonia cinerea leaves: Comparing response surface methodology and artificial neural network," Beni-Suef University Journal of Basic and Applied Sciences, vol. 7, no. 3, pp. 276-285, 2018.

[2] R. Rajamurugan, N. Selvaganabathy, S. Kumaravel et al., "Identification, quantification of bioactive constituents, evaluation of antioxidant and in vivo acute toxicity property from the methanol extract of Vernonia cinerea leaf extract," Pharmaceutical Biology, vol. 49, no. 12, pp. 1311-1320, 2011.

[3] N. Ketsuwan, J. Leelarungrayub, S. Kothan, and S. Singhatong, "Antioxidant compounds and activities of the stem, flower, and leaf extracts of the anti-smoking Thai medicinal plant: Vernonia cinerea Less," Drug Design, Development and Therapy, vol. 11, pp. 383-391, 2017.

[4] N. Ketsuwan, J. Leelarungrayub, and C. Banchonglikitkul, "Effects of Thai medicinal plant, Vernonia cinerea Less. extract 
on catecholamine, oxidative stress and chromosome aberration in nicotine-treated rats," Journal of Associated Medical Sciences, vol. 50, no. 2, pp. 262-274, 2017.

[5] O. R. Alara, N. H. Abdurahman, and C. I. Ukaegbu, "Soxhlet extraction of phenolic compounds from Vernonia cinerea leaves and its antioxidant activity," Journal of Applied Research on Medicinal and Aromatic Plants, vol. 11, pp. 12-17, 2018.

[6] U. K. Mazumder, M. Gupta, L. Manikandan, S. Bhattacharya, P. K. Haldar, and S. Roy, "Evaluation of anti-inflammatory activity of Vernonia cinerea Less. extract in rats," Phytomedicine, vol. 10, no. 2-3, pp. 185-188, 2003.

[7] A. Saraphanchotiwitthaya and P. Sripalakit, "Anti-inflammatory activity of a Vernonia cinerea methanolic extract in vitro," ScienceAsia, vol. 41, no. 6, pp. 392-399, 2015.

[8] P. Pratheeshkumar and G. Kuttan, "Protective role of Vernonia cinerea L. against gamma radiation-induced immunosupression and oxidative stress in mice," Human \& Experimental Toxicology, vol. 30, no. 8, pp. 1022-1038, 2011.

[9] N. K. Dogra and S. Kumar, "A review on ethno-medicinal uses and pharmacology of Vernonia cinerea Less," Natural Product Research (Formerly Natural Product Letters), vol. 29, no. 12, pp. 1102-1117, 2015.

[10] C. Naijitra and A. Cheoymang, "Evaluation of antioxidant activity, total phenolic and nicotine contents of 15 Thai herbs," Thai Journal of Science and Technology, vol. 24, no. 2, pp. 351361, 2016.

[11] A. Chaikoolvatana, N. Ayuthaya, P. Suthipinittharm, C. Chaikoolvatana, N. Saisingh, and M. Manwong, "Development and evaluation of the effectiveness of Vernonia cinerea (VC) cookies for smoking cessation," Journal of Health Research, vol. 31, no. 1, pp. 23-32, 2017.

[12] A. Chaikoolvatana, J. Thanawirun, C. Chaikoolvatana et al., "Use of Vernonia cinerea jelly candies for smoking cessation, Ubon Ratchathani region, Thailand," EnvironmentAsia, vol. 11, no. 2, pp. 172-191, 2018.

[13] S. Wongwiwatthananukit, P. Benjanakaskul, T. Songsak, S. Suwanamajo, and V. Verachai, "Efficacy of Vernonia cinerea for smoking cessation," Journal of Health Research, vol. 23, no. 1, pp. 31-36, 2009.

[14] P. Puttarak, P. Pornpanyanukul, T. Meetam, K. Bunditanukul, and N. Chaiyakunapruk, "Efficacy and safety of Vernonia cinerea (L.) Less. for smoking cessation: A systematic review and meta-analysis of randomized controlled trials," Complementary Therapies in Medicine, vol. 37, pp. 37-42, 2018.

[15] M. Punyaratabandha, P. Chuanchaum, and S. Somwatasun, "Efficacy of Vernonia cinerea for smoking compared with tea (Camellia sinensis)," Chonburi Hospital Journal, vol. 34, no. 3, pp. 133-140, 2009.

[16] P. Kuwivattanachai and S. Moto, "A comparison of Vernonia cinerea and placebo for smoking cessation," Srinagarind Medical Journal, vol. 32, no. 6, pp. 542-546, 2017.

[17] W. Tripopskul and C. Sittipunt, "Efficacy of Vernonia cinerea for smoking cessation in Thai active smokers," 2011, http://www .trc.or.th/trcresearch/subpage/RP/TRC_Re_53-01-18.pdf.

[18] S. Kitpaiboontawee, "Efficacy of Vernonia cinerea lozenge as an adjunct to pharmacist counseling on smoking abstinence rate : A randomized controlled trial," 2012, http://www.trc.or.th/ trcresearch/subpage/TS/TRC_Th_55-001-01.pdf.

[19] D. Leelarungrayub, S. Pratanaphon, P. Pothongsunun, T. Sriboonreung, A. Yankai, and R. J. Bloomer, "Vernonia cinerea Less. supplementation and strenuous exercise reduce smoking rate: Relation to oxidative stress status and beta-endorphin release in active smokers," Journal of the International Society of Sports Nutrition, vol. 7, p. 21, 2010.

[20] S. Jitpukdeebodintra and A. Jangwang, "Coffee for smoking cessation," Journal of Food, Agriculture and Environment (JFAE), vol. 7, no. 3-4, pp. 130-133, 2009.

[21] S. Srisoi, S. Lertsinudom, J. Areemit et al., "Efficacy and safety of Vernonia cinerea pastilles for smoking cessation in low and moderate nicotine dependence," Isan Journal of Pharmaceutical Sciences, vol. 14, no. 4, pp. 68-78, 2018.

[22] R. M. Smith, "Before the injection-modern methods of sample preparation for separation techniques," Journal of Chromatography A, vol. 1000, no. 1-2, pp. 3-27, 2003.

[23] J. Azmir, I. S. M. Zaidul, M. M. Rahman et al., "Techniques for extraction of bioactive compounds from plant materials: a review," Journal of Food Engineering, vol. 117, no. 4, pp. 426-436, 2013.

[24] M. A. Bezerra, R. E. Santelli, E. P. Oliveira, L. S. Villar, and L. A. Escaleira, "Response surface methodology (RSM) as a tool for optimization in analytical chemistry," Talanta, vol. 76, no. 5, pp. 965-977, 2008.

[25] C. Monton, S. Settharaksa, C. Luprasong, and T. Songsak, "An optimization approach of dynamic maceration of Centella asiatica to obtain the highest content of four centelloids by response surface methodology," Revista Brasileira de Farmacognosia, 2019.

[26] C. F. Cheng and C. W. Tsang, "Simultaneous determination of nitrite, nitrate and ascorbic acid in canned vegetable juices by reverse-phase ion-interaction HPLC, Food Additives \& Contaminants: Part A, vol. 15, no. 7, pp. 753-758, 1998.

[27] S.-S. Chou, J.-C. Chung, and D.-F. Hwang, "A high performance liquid chromatography method for determining nitrate and nitrite levels in vegetables," Journal of Food and Drug Analysis, vol. 11, no. 3, pp. 233-238, 2003.

[28] C. Monton, B. Boonkrungthong, S. Settharaksa et al., "Method validation and quantitation of sodium nitrate in $0.5 \%$ sodium nitrate mouthwash for smoking cessation," Bulletin of Health, Science and Technology, vol. 14, no. 2, pp. 33-39, 2016.

[29] C. Monton, L. Charoenchai, J. Suksaeree, and B. Boonkrungthong, "Forced degradation study of sodium nitrate solution and its formulation," Thai Journal of Pharmaceutical Sciences, vol. 41, no. Supplement, pp. 45-48, 2017.

[30] K. K. Chew, S. Y. Ng, Y. Y. Thoo, M. Z. Khoo, W. M. Wan Aida, and C. W. Ho, "Effect of ethanol concentration, extraction time and extraction temperature on the recovery of phenolic compounds and antioxidant capacity of Centella asiatica extracts," International Food Research Journal, vol. 18, no. 2, pp. 571-578, 2011.

[31] W.-F. Lv, M.-Y. Ding, and R. Zheng, "Isolation and quantitation of amygdalin in Apricot-kernel and Prunus tomentosa Thunb. by HPLC with solid-phase extraction," Journal of Chromatographic Science (JCS), vol. 43, no. 7, pp. 383-387, 2005.

[32] Y. Liu, M. Qiang, Z. Sun, and Y. Du, “Optimization of ultrasonic extraction of polysaccharides from Hovenia dulcis peduncles and their antioxidant potential," International Journal of Biological Macromolecules, vol. 80, pp. 350-357, 2015.

[33] S. Tian, C. Hao, G. Xu, J. Yang, and R. Sun, "Optimization conditions for extracting polysaccharide from Angelica sinensis and its antioxidant activities," Journal of Food and Drug Analysis, vol. 25, no. 4, pp. 766-775, 2017.

[34] J. Wang, Y. Zhao, W. Li, Z. Wang, and L. Shen, “Optimization of polysaccharides extraction from Tricholoma mongolicum 
Imai and their antioxidant and antiproliferative activities," Carbohydrate Polymers, vol. 131, pp. 322-330, 2015.

[35] C. Chen, L.-J. You, A. M. Abbasi, X. Fu, and R. H. Liu, "Optimization for ultrasound extraction of polysaccharides from mulberry fruits with antioxidant and hyperglycemic activity in vitro," Carbohydrate Polymers, vol. 130, pp. 122-132, 2015.

[36] H. Shang, M. Wang, R. Li, M. Duan, H. Wu, and H. Zhou, "Extraction condition optimization and effects of drying methods on physicochemical properties and antioxidant activities of polysaccharides from Astragalus cicer L," Scientific Reports, vol. 8, no. 1, p. 3359, 2018.

[37] J. R. Vergara-Salinas, J. Pérez-Jiménez, J. L. Torres, E. Agosin, and J. R. Pérez-Correa, "Effects of temperature and time on polyphenolic content and antioxidant activity in the pressurized hot water extraction of deodorized thyme (Thymus vulgaris)," Journal of Agricultural and Food Chemistry, vol. 60, no. 44, pp. 10920-10929, 2012.

[38] M. Dent, V. Dragović-Uzelac, M. Penić, M. Brñić, T. Bosiljkov, and B. Levaj, "The effect of extraction solvents, temperature and time on the composition and mass fraction of polyphenols in dalmatian wild sage (Salvia officinalis L.) extracts," Food Technology and Biotechnology, vol. 51, no. 1, pp. 84-91, 2013.

[39] F. S. Martins and E. C. Da Conceição, "Evaluation of extraction method on the chemical composition in Apeiba tibourbou Aubl's extracts," Pharmacognosy Magazine, vol. 11, no. 42, pp. 368-373, 2015.

[40] M. Kuzmanović, M. Tišma, A. Bucić-Kojić et al., "High-pressure and temperature extraction of phenolic compounds from corn silage," Chemical Engineering Transactions, vol. 43, pp. 133-138, 2015.

[41] S. Duangjit, Y. Obata, H. Sano et al., "Menthosomes, novel ultradeformable vesicles for transdermal drug delivery: Optimization and characterization," Biological \& Pharmaceutical Bulletin, vol. 35, no. 10, pp. 1720-1728, 2012.

[42] S. Duangjit, L. M. Mehr, M. Kumpugdee-Vollrath, and T. Ngawhirunpat, "Role of simplex lattice statistical design in the formulation and optimization of microemulsions for transdermal delivery," Biological \& Pharmaceutical Bulletin, vol. 37, no. 12, pp. 1948-1957, 2014. 


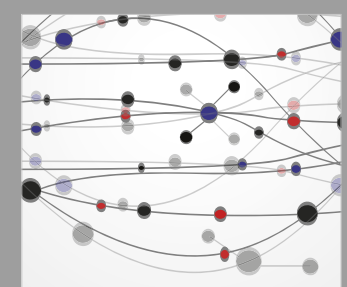

The Scientific World Journal
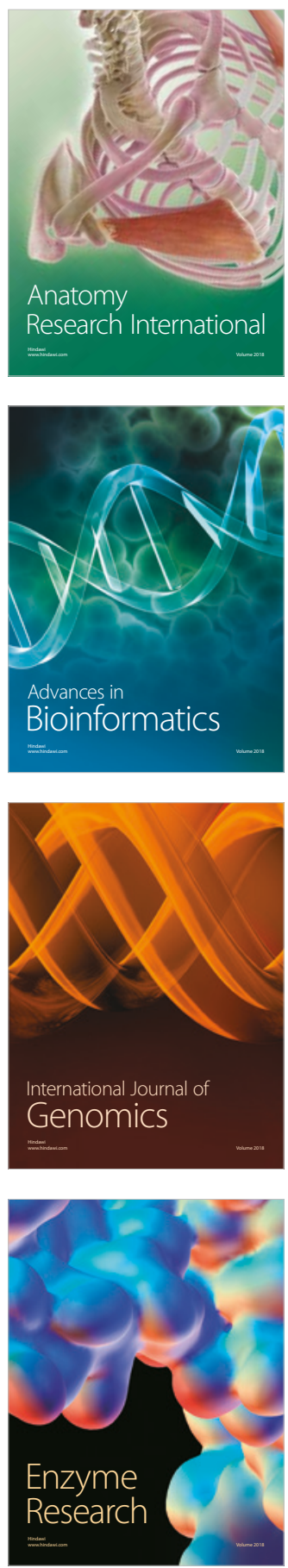
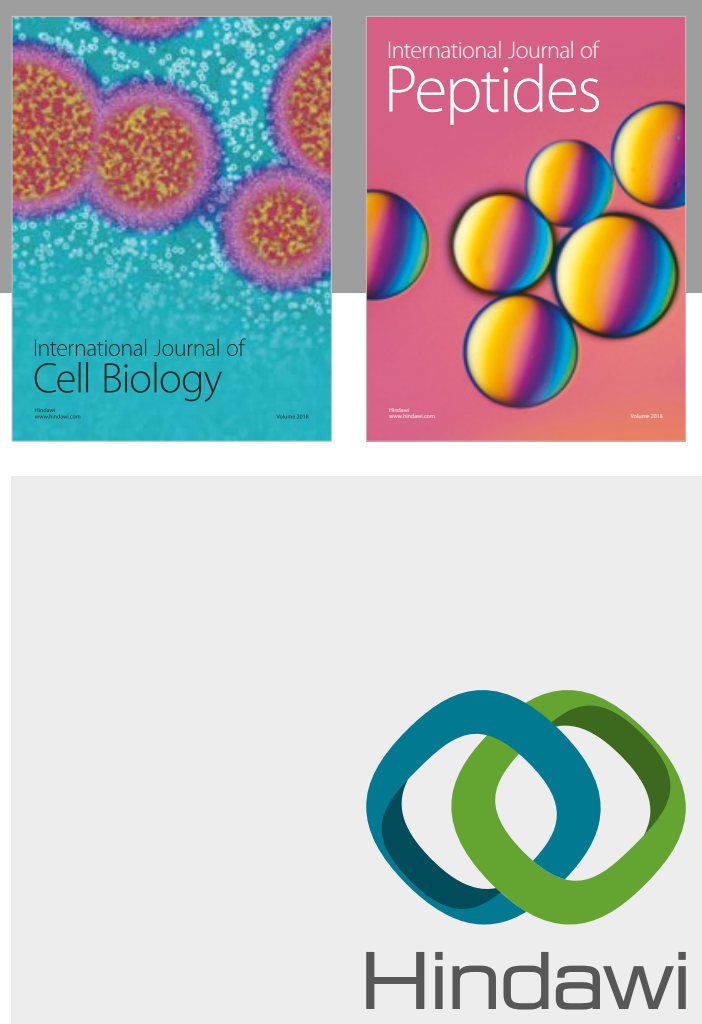

Submit your manuscripts at

www.hindawi.com
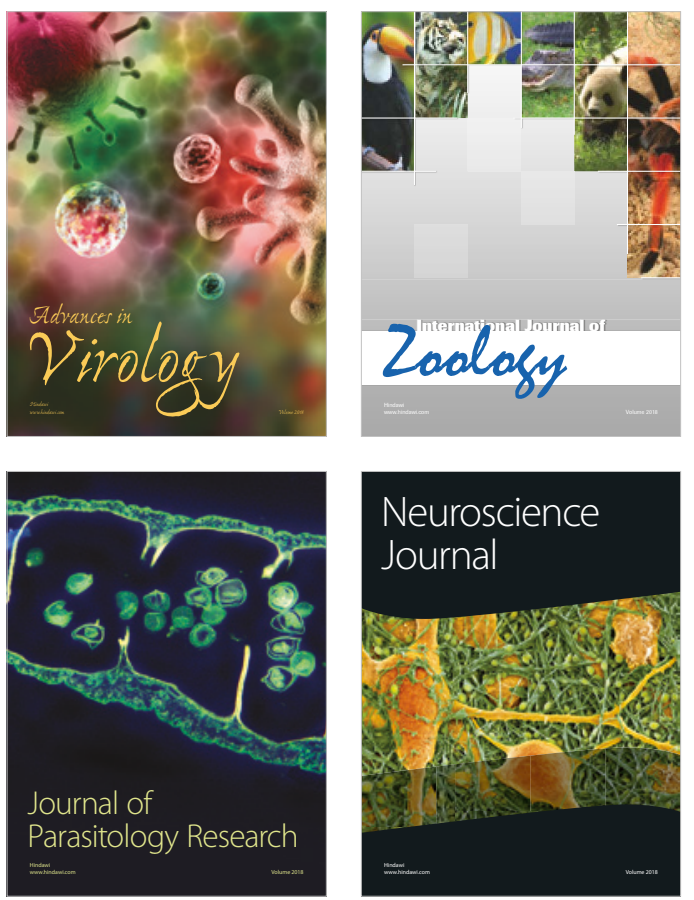
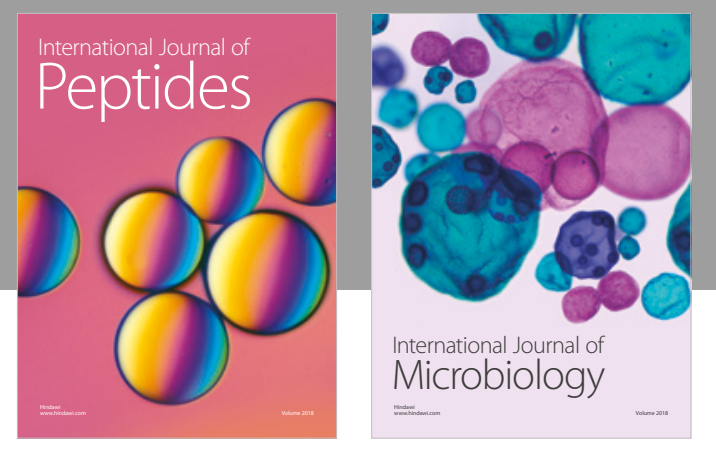

nternational Journal of Microbiology
Journal of
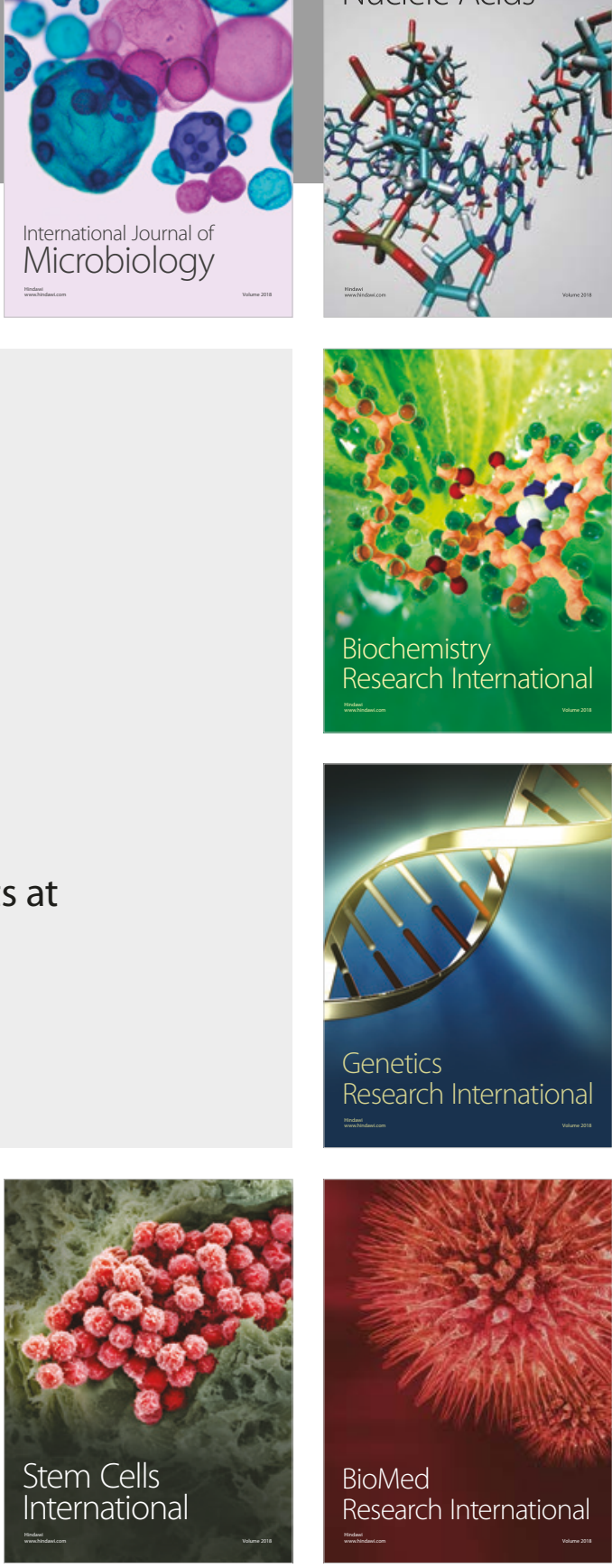
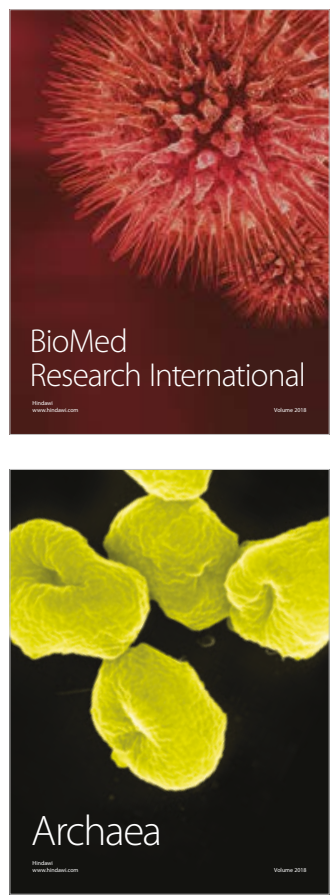